\title{
Beyond the Dyad: Employee Networks, Social Influence, and the Performance of Interpersonal Forms of Citizenship Behavior
}

\author{
Randall Settoon \\ Southeastern Louisiana University, United States
}

Received: July 15, 2019 Accepted: August 6, 2019 Online published: August 12, 2019

doi:10.5296/ijhrs.v9i3.15076 URL: https://doi.org/10.5296/ijhrs.v9i3.15076

\begin{abstract}
The purpose of this study is to explore the relationship between ICB performance and three network properties theorized to produce behavioral conformance: strong ties, relational embeddedness, and structural equivalence. Results of a multiple regression QAP of sociometric data provided by 33 facilities and maintenance employees of a large medical center showed that structurally equivalent employees performed similar levels of both instrumental and supportive ICB. Additionally, relational embeddedness was associated with similarity in the performance of supportive ICB. Interestingly, the network variables explained variance in ICB beyond that explained by antecedents of high-quality, dyadic exchange. These findings provide evidence that the larger social context can produce conformity in ICB performance through symbolic role-taking and normative compliance processes.
\end{abstract}

Keywords: interpersonal citizenship behavior, social networks, social influence

\section{Introduction}

A considerable amount of research attention has been devoted to the study of various forms of organizational citizenship behavior (Ocampo, Acedillo, Bacunador, Balo, et al., 2018). A fundamental assumption driving much of this research is that, in the aggregate, citizenship behavior is critical to organizational functioning and performance (Organ, 1988). Interpersonal citizenship behavior (ICB) (Settoon \& Mossholder, 2002) is one form of organizational citizenship considered to have important implications for organizations. Generally defined as discretionary, helpful behavior directed at coworkers, ICB enhances individual and group productivity, frees resources, increases coordination, and contributes to a favorable work climate (Lepine \& Van Dyne, 2001; Moorman, 1993; Settoon \& Mossholder, 2002; Williams \& Anderson, 1991). Beyond its instrumentality for enhanced work 
performance, ICB has symbolic value (Podsakoff, Whiting, Podsakoff \& Blume, 2009). Its performance is a means of demonstrating the intrinsic value an employee places on a close relationship with another.

Because ICB is a social behavior, social exchange theory (Blau, 1964) has been used to frame important research questions. Studies have consistently found employees' perceptions of the quality of their dyadic-exchange relationships to be associated with the performance of ICB (Cropanzano \& Mitchell 2005). While these studies have articulated important relational antecedents, their dyadic focus has offered a somewhat limited view of how the social context influences ICB. It is likely that important social processes operating "beyond the dyad" influence ICB performance (Chen, Takeuchi \& Shum, 2013). Yet, these processes have received limited research attention in the citizenship behavior literature.

Recent conceptual frameworks articulating links between citizenship behavior and organizational performance have highlighted the important role of ICB in developing and sustaining social networks. For example, Bolino, Turnley, and Bloodgood (2002) offer that ICB generates social capital, which is essential for sustaining an organization's competitive advantage. Constituted by networks of relational ties, social capital is the stock of positive sentiment in the social context that enhances an organization's capacity to effectively and efficiently mobilize resources for purposive actions (Adler \& Kwon, 2002). Social capital is created by cooperative engagement and emboldens important social dynamics such as positive sentiment, shared understandings, and trust (Coleman 1990). As such, the social capital framework necessarily positions ICB as entangled within a larger social context of employee social networks, thereby implicating the importance of social context in shaping ICB performance.

Studies using social network methodology have found links between network properties and the performance of citizenship behaviors (e.g., Venkataramani \& Dalal, 2007; Zagenczyk, Gibney, Murrell \& Boss, 2008). Interestingly, the results of these studies have shown network variables to explain variance in ICB performance beyond that which is explained by traditionally researched, attitudinal antecedents. Explanations for the link between network properties and ICB performance are grounded in social information processing and other social cognitive theories, which posit that people who interact with each other regularly are more likely to have similar perceptions and behaviors than people who do not interact (Salancik \& Pfeffer 1978). Further, employees are most susceptible to social influence when they experience ambiguous situations.

The purpose of this study is to explore the impact on ICB performance of three network properties that produce attitudinal and behavioral conformity: strong ties, relational embeddedness, and structural equivalence. The findings of prior studies suggest that these three network properties enable social influence through frequent interaction, normative enforcement, and symbolic role-taking, respectively (Meyer, 1994). Additionally, the predictive power of the network variables as compared to perceptions of trust and obligations to reciprocate, two social exchange antecedents, is examined. The results of the study will provide additional insight regarding which network properties, and by association, which social influence mechanisms are most important for engendering ICB performance. 


\section{ICB Performance and Social Influence}

It goes without saying that in most organizations where employees are co-located, work roles and processes will require that employees interact to address problems and other performance contingencies. As a result, ICB is thought to be a pervasive behavior in organizations that is shaped by, and shapes, the social context of an employee (Brass, 2018). Generally, ICB is helping behavior, and by definition helping interactions are purposive (i.e., established for a reason such as problem-resolution) and involve the transfer of resources (material and psychosocial) from one to another (Bamberger, 2009; Ehrhart, 2018). While ICB may be performed proactively (Bateman \& Crant, 1993), it is also performed in response to a direct helping request by a coworker or as a means to reciprocate help received from a coworker. As such, ICB is an instrumental behavior that is consequential for work performance and for the maintenance of relational ties between coworkers (Organ, 1997).

Importantly, citizenship behavior is conceptualized as being extra-role behavior that is not generally recognized by the formal reward system of an organization. While it can be given or withheld at will by an employee, some have argued that ICB is more likely to be withheld than given (Bergeron, 2007). Although ICB performance can lead to positive consequences for an employee (Podsakoff, Whiting, Podsakoff \& Blume, 2009), its performance can be materially, socially, and/or psychologically costly (Bergeron, 2007; Deery, Rayton, Walsh \& Kinnie, 2016). For example, employees who give help may find that they are being taken advantage of, or that they have unknowingly committed themselves to an interaction that requires more time, energy and effort than anticipated. Additionally, it may be viewed as risky if the act of redirecting resources to enable another's performance comes at a cost to that employee's own performance and career advancement (Bergeron, 2007).

The tension between managing the personal risks of helping and preserving relational ties requires that individuals form accurate perceptions regarding others' expectations for their behavior. Because expectations for the performance of extra-role behaviors like ICB are generally ill-defined and subject to multiple interpretations, employees will attend to salient cues in the social context to evaluate the priority to place on them. Morrison (1994) offered that social cues influence the extent to which employees will redefine discretionary behavior as in-role behavior (i.e., part of the job). The more a behavior is defined as in-role, the less discretionary the behavior is perceived to be, and the more it will be performed. In sum, given the uncertainty produced by lack of objective standards upon which to accurately determine expectations for ICB, it is likely that employees will attend to cues and information in the social context to properly orient themselves to its performance (Cialdini \& Goldstein, 2003). 


\section{Hypotheses}

Research has found that coworkers influence a variety of behaviors, including organizational citizenship behavior (e.g., Bommer, Miles \& Grover, 2003). Influence occurs when individuals attend to relevant contextual cues and socially derived interpretations of events and their meanings to form their own attitudes and opinions. According to Salancik and Pfeffer (1978), the social context focuses an individual's attention on certain aspects of the work environment and away from others, and provides expectations concerning individual behavior and the personal consequences of such behavior. Conformity results as employees adjust their attitudes and actions to align with those of their coworkers (Brass \& Burkhardt, 1993; Salancik \& Pfeffer, 1978).

Social networks provide the structural context by which people are proximate to others' information, influence, and behavior, and relational ties are the conduit through which social influence flows (Ibarra \& Andrews, 1993; Rice \& Aydin, 1991; Wasserman \& Faust, 1994). Relational ties function as decision-making, knowledge-sharing, instrumental, and emotional support systems (Kram \& Isabella, 1985; Rawlins, 1992). Through these ties, employees are exposed to similar social information, and as a result, similarly conform their perceptions, attitudes, and behavior (e.g., Gibbons, 2004; Umphress, Labianca, Brass, Kass, et al., 2003). Three network properties that enable social influence processes have been identified: strong ties, relational embeddedness and structural equivalence (see Figure 1). Their link to ICB performance through social influence processes are hypothesized below.

\subsection{Strong Ties}

Work processes in the task environment demand that employees interact with coworkers whom they are dependent, and who are dependent on them. Interaction over time can generate stable, enduring relational ties, and the social cues that employees attend to are largely derived from these ties (Katz \& Kahn 1978). Coworkers who are familiar with the work of an employee play a greater role in shaping that employee's attitudes and behaviors than coworkers who have little interaction with that employee (Burkhardt, 1994). Strong relational ties reflect frequent contact, emotional intensity, self-disclosure, and reciprocity, and produce reliable and trustworthy information within them (Granovetter, 1973). As a result, strong relational ties exert influence more effectively. Additionally, strong ties encourage feedback-seeking, which in turn helps employees disentangle multiple interpretations of what is (is not) expected in their work roles (Bhave, Kramer \& Glomb, 2010; Chen, Lam \& Zhang, 2007; Vinarski-Peretz, Binyamin \& Carmeli, 2011). 
$\mathrm{H} 1$

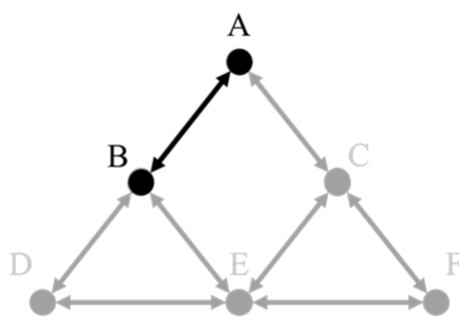

Strong Tie
$\mathrm{H} 2$

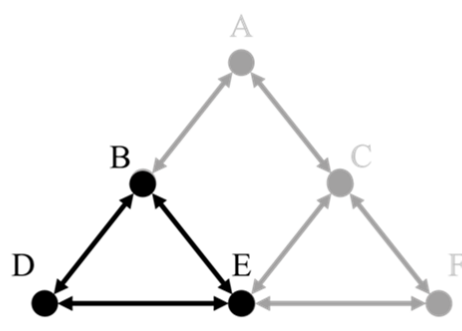

Relational Embeddedness
H3

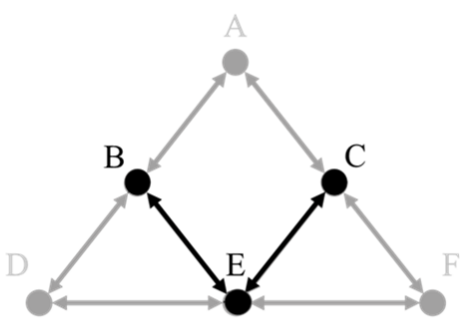

Structural Equivalence $\underline{\text { Network Property }}$

H1 Strong Tie

H2 Relational

Embeddedness

H3 Structural

Equivalence

\section{Example Prediction}

Figure 1. Predictions of ICB similarity based on network property

Importantly, strong ties promote self-disclosure and, in general, they facilitate a more intimate understanding of common problems faced by coworkers at work, their causes, the availability of helping resources, and knowledge of the outcomes of helping episodes (Sherony \& Green 2002). The processing of this information leads to a shared, socially constructed meaning of helping episodes that provides clarity regarding how to respond to them. As a result, two employees connected by a strong tie will incorporate a similar orientation toward ICB performance, and this orientation will be used when responding to requests for help or when discharging obligations to reciprocate.

Hypothesis 1: The stronger the tie connecting two employees the more similar their ICB performance will be. 


\subsection{Relational Embeddedness}

Benefits accrue to groups of highly interconnected employees in organizations. Overlapping ties enable normative pressures that produce conformity in attitudes and behavior (Bolino, Turnley \& Bloodgood, 2002; Coleman, 1990; Granovetter, 1973; Krackhardt, 1999). Bommer et al. (2003) found that the level of helping behaviors performed by an employee's coworkers in a small cohesive work group influenced the level of helping behavior performed by that employee. When the level was high (low), the employee similarly helped more (less). Groups of employees will enact shared norms to sustain and maximize the value and benefits that accrue from cohesive relational ties (Brass, Butterfield \& Skaggs, 1998). Pressures for compliance reduce uncertainty and ambiguity surrounding interpersonal interaction and clarify standards for behavior.

In social networks, normative compliance pressures are found to operate in a connected triad (also referred to as a clique or closed network), where two employees who interact also interact with a common third party. In building network connections, employees have a tendency to extend new relational ties through established ties (i.e., ties are extended to "friends of a friend") (Bowler \& Brass, 2006; Kilduff \& Brass, 2010). The more that an employee's network of relational ties overlap with those of coworkers, the more triads that an employee is a member of, and thus, the more embedded is the employee in the social structure.

Through the effect of the third-party tie, network triads are a particularly strong source for normative compliance pressures. Because all parties in a triadic structure have knowledge of the outcomes of interpersonal interaction, two employees will interact in socially prescribed ways for the purpose of preserving the tie with the common third-party. As seen in Figure 1 (H2), if employee D has a relational tie with employee E, and both employee D and E have a relational tie with employee $\mathrm{B}$, then employee $\mathrm{D}$ and employee $\mathrm{E}$ will perform ICB directed at each other as normatively prescribed to retain favor with employee B. In sum, embeddedness produces strong normative compliance pressures that affect the behavior between two employees with a relational tie. It is hypothesized that the more third parties that two employees have in common (i.e., the more relationally embedded they are), the more similar will be their ICB performance.

Hypothesis 2: The more third parties that two employees have in common, the more similar their ICB performance will be.

\subsection{Structural Equivalence}

There are consequences to occupying a certain structural position in a network. Like the formal hierarchy of an organization defines access to resources and who reports to whom, so does the structure of an informal employee network. Additionally, like similar positions in the formal hierarchy produce similar pressures that affect role definitions, so do similar positions in the informal hierarchy (Brass \& Burkhardt, 1993; Shah, 1998). Employees who have similar access to resources, or who possess similar resources themselves (e.g., task mastery, knowledge, and expertise), will occupy similar status positions in the network. By extension, 
similar status employees will have similar patterns of relational ties (i.e., structural equivalence).

Roles and role obligations are defined by position in a network (Ho, 2005; Morrison, 1994), and employees monitor structurally equivalent employees to acquire job-relevant information (Shah, 1998). Because they are similarly positioned in an information field, they will experience similar pressures to conform (Hartman \& Johnson, 1989). As a result, they will tend to see each other as a relevant referent for comparison (Ho \& Levesque, 2005). As seen in Figure $1(\mathrm{H} 3)$, if employee B frequently helps employee $\mathrm{E}$, and employee $\mathrm{C}$ also helps employee $\mathrm{E}$, employees $\mathrm{B}$ and $\mathrm{C}$ are structurally equivalent through their similar positions with regard to employee E. Employees B and C will attend to cues provided by the other in order to better align their own behavior with the common role they occupy. It is hypothesized:

Hypothesis 3: The more structurally equivalent two employees are, the more similar their ICB performance will be.

\section{Method}

In this study, social network analysis was used to model the social context and to identify the network properties hypothesized to be associated with the performance of ICB. Data for analysis was collected as part of a larger study of a regional medical center. In that study, 374 surveys were distributed to employees working in 50 departments. A total of 215 surveys were usable (58 percent response rate). In network analysis, completeness of data is important because the methodology is more sensitive to missing data than other research methods. Generally, a network response rate of at least 75 percent is required for limiting the possible negative effects of missing data and for the results of analyses to be considered reliable (Borgatti, Carley \& Krackhardt, 2006; Wasserman \& Faust, 1994).

To identify an acceptable network population from the hospital data, the size and response rate for each department were reviewed, as well as the concentration of ties between employees within each department and external to it. The goal was to identify a bounded network that would meet minimum standards for network response rates. Given that proximity is a strong determinant of the formation of network ties (Brass, 2018), the response rate by department was examined. For departments exceeding the 75 percent response-rate requirement, the number of ties between employees that were internal to the department versus external to the department were analyzed. A department having an acceptable response rate and whose employee network is clearly bounded (i.e., minimal external ties) would be used for the study.

Compared to all other departments, the facilities and maintenance department had the largest number of employees with the highest response rate (i.e., 33 out of 40 employees completed surveys for a response rate of 83\%), and had the largest negative E-I Index (-.67), which is indicative of a network having primarily internal ties (Krackhardt \& Stern, 1988). Briefly, the E-I (external-internal) index takes the number of ties of group members to outsiders, subtracts the number of ties to other group members, and divides by the total number of ties. The 
resulting index ranges from -1 (all ties are internal to the group) to +1 (all ties are external to the group). By comparison, the nursing unit also had an E-I index of -.67. However, only 23 of 53 employees completed surveys for a response rate of 43 percent (which falls well below the required response rate of $75 \%$ ). Therefore, hospital employees working in the facilities and maintenance department were selected as the sample for the study. Fifty-two percent of the employees were female, 46 percent were caucasian, 80 percent had a high school degree, the average age was 40.7 years, and the average organizational tenure was 7.5 years.

\subsection{Measures}

Data was collected from multiple sources using different formats to elicit responses. Surveys containing multi-item measures and a sociometric question were completed by employees. The sociometric question asked employees to list the coworkers with whom they interact frequently. Additionally, employees were asked to list the coworkers they go to for help when they have a problem. Responses were used to construct network adjacency matrices from which network measures were created. A separate survey was completed by supervisors who assessed each employee's performance of ICB. Finally, demographic information was collected and used as controls.

\subsubsection{Similarity in ICB Performance}

Researchers examining social influence have used measures of dyadic similarity between employees to test their hypotheses (e.g. Burkhardt, 1994; Ibarra \& Andrews, 1993; Umphress, et al., 2003). To calculate the extent to which an employee's ICB performance was similar to his or her coworkers, we first measured ICB performance using a 14-item ICB scale developed by Settoon and Mossholder (2002). The measure has two subscales: Instrumental ICB (IICB) and Supportive ICB (SICB). The IICB subscale includes six items that measure task-focused helping $(\alpha=.95$; e.g., "Helps coworkers with difficult assignments, even when assistance is not directly requested"). The SICB subscale includes eight items that measure person-focused, supportive behavior ( $\alpha=.93$; e.g., "Listens to coworkers when they have to get something off their chest"). For each employee, supervisors indicated their level of agreement with each item on a 5-point Likert-type scale ranging from "1" (strongly disagree) to " 5 " (strongly agree).

Next, an index of similarity in ICB performance between every possible pair of employees in the sample was created. Specifically, a 33 x 33 similarity matrix was created for IICB and SICB performance, where the rows and columns in the matrix represented all employees, and the cells at the intersection of a row and column represented the degree of similarity. With regard to ICB performance and the other non-network measures, similarity was computed by taking the absolute difference between one employee's score on a focal measure and a coworker's score on the same measure, and reversing the resulting difference score such that larger numbers represented greater similarity between two employees. As a result, each matrix contained $(\mathrm{N} \times(\mathrm{N}-1))$ cells, or 1,056 observations, each representing a similarity index between every pair of employees in the study. 


\subsubsection{Network Measures}

From the sociometric data, two adjacency matrices were created and were the source for the network measures. An adjacency matrix was constructed based on who employees indicated they interacted with frequently (i.e., the interaction matrix). A cell in the matrix was coded with a " 1 " if an employee (row) interacted frequently with a coworker (column). The cell was coded with a "0" if no interaction was indicated by either employee. A second matrix was constructed based on who each employee listed as coworkers from whom they sought help. Similar to the interaction matrix, a cell in this matrix was coded with a "1" if an employee (row) sought help from a coworker (column). Because the focus of the study is the performance of ICB, this second matrix was transposed to create a help-giving adjacency matrix.

Strong Ties. A strong tie between two employees is one that is characterized by interaction, intensity, and reciprocity (Granovetter, 1973). To create a measure of tie strength, the interaction adjacency matrix was symmetrized and cells were summed. Cell values in the resulting matrix range from zero to two: a "0" indicates that two employees do not interact frequently; a "1" indicates at least one of the two employees mentioned frequent interaction with the other; and a "2" indicates reciprocity in that both employees mentioned frequent interaction with each other (e.g., Zagenczyk, et al., 2008).

Relational Embeddedness. The extent to which two employees who frequently interact also interact with a common third-party coworker was used as the measure of structural embeddedness. In an adjacency matrix, a walk of length two between two employees reflects the presence of a coworker with whom two employees both have a tie. The more two employees with a relational tie also have a tie with a common third-party, the more they are embedded. To calculate the number of walks of length two (i.e., the number of ties to common third-parties), the interaction adjacency matrix was multiplied by itself. Thus, the interaction matrix was squared, yielding a 33 x 33 matrix where the value of each cell represents the number of ties to third-parties two employees have in common. The larger the number of common third-party ties, the greater the structural embeddedness of two employees.

Structural Equivalence. Employees are structurally equivalent to the extent that the character of the relationships they share with coworkers are similar, regardless of whether they are connected themselves. It is a way to formalize the concept of position and role. The degree of structural equivalence between two employees was computed using the Pearson product coefficient for each pair of actors based on their row and column cell values in the help-giving adjacency matrix. The help-giving matrix remained asymmetric in this analysis as directional matrices offer additional information regarding position (i.e., who is helping whom rather than simply the presence of a helping tie). 


\subsubsection{Control Variables}

Several control variables were included in the model. ICB performance has been consistently found to be associated with high-quality exchange relationships, which are characterized by reciprocity and trust. In this study, employees provided information on their general perceptions of obligations to reciprocate and trust in coworkers. Obligations to reciprocate was measured with three items reflecting psychological feelings of indebtedness $(\alpha=.67$; e.g., "My coworkers have done things for me that I feel I should repay them for"). Trust in coworkers was measured using McAllister's (1995) Affect-Based Trust Scale $(\alpha=.85$; e.g., "If I had a problem at work, I know my coworkers would respond constructively and caringly"). Additionally, information on gender ( $1=$ male; 2 = female), education level ( $1=$ high school; 2 = college degree; 3 = graduate degree), and tenure (years employed with organization) were collected. Consistent with the process used for the non-network matrices, similarity matrices were created for all control variables.

\section{Analysis and Results}

The multiple regression quadratic assignment procedure (QAP) in UCINET 6 was used to test the hypotheses (Borgatti, Everett \& Freeman, 2002). Because observations used to create social network variables are non-independent, use of traditional OLS regression procedures for testing hypotheses are inappropriate (Krackhardt, 1988). QAP is resistant to the effects of autocorrelation among error terms because it uses permutation-based tests of significance. The procedure regresses individual cells of a dependent (variable) matrix on the corresponding cells in multiple predictor (variable) matrices to generate a regression coefficient. To estimate the standard error, all rows and columns from the dependent (variable) matrix are permuted randomly and the regression coefficient is recomputed many times. Statistics are provided that indicate the proportion of recomputed regression coefficients that are as extreme as the one calculated from the un-permuted dependent (variable) matrix. If a low proportion of similar results are found, a significant relationship is indicated (Raider \& Krackhardt, 2001).

Because the quadratic assignment procedure utilizes permutation-based tests of hypotheses, degrees of freedom are not calculated (Ferrin, Dirks \& Shah, 2006). Additionally, the structure of network data limits the possible number of correlations. As a result, equivalent correlations and beta values may not represent equal levels of significance and $R^{2}$ values may be smaller than regular OLS regression. Therefore, the primary statistic of interest is the $p$-value generated from the permutations (Gibbons, 2004). 
Table 1. QAP Correlations

$\begin{array}{lllllllllll}\underline{M} & \underline{S D} & 1 & 2 & 3 & 4 & 5 & 6 & 7 & 8 & 9\end{array}$

1. IICB

2. SICB

3. Gender

4. Education

5. Tenure

6. Obligation

7. Trust

8. Strong Ties

9. Embedded

10. Equivalent
$2.19 \quad .33$

$2.00 \quad .27 \quad .58 * *$

$.49 \quad 02 \quad .04+\quad .15^{* *}$

$\begin{array}{lllll}.64 & .30 & .04 & -.10 & -.01\end{array}$

$\begin{array}{llllll}23.00 & 4.56 & .00 & .06 & -.03 & -.15\end{array}$

$\begin{array}{lllllll}2.56 & .46 & .12 & -.01 & -.02 & .40 * * & .05\end{array}$

$\begin{array}{llllllll}2.10 & .33 & .15+ & .08 & .00 & .03 & -.08 & .24 * *\end{array}$

$\begin{array}{lllllllll}1.28 & .24 & .01 & .09 * & .27 * * & .08+ & .06 & .02 & .08 *\end{array}$

$\begin{array}{llllllllll}1.25 & .49 & .02 & .07 & .33^{* *} & .10+ & .03 & .08 & .10 * & .36 * *\end{array}$

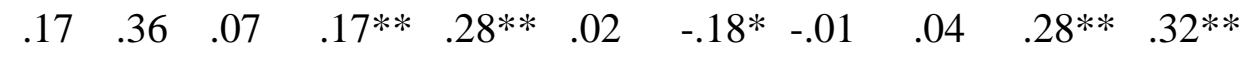

Note: Means and standard deviations for non-network matrices are similarity indices. Similarity indices were computed by taking the absolute value of the difference between two employees on the focal variable. The index was reversed such that a higher value indicates greater similarity. Descriptive statistics for strong ties and relational embeddedness reflect the values of relational ties that exist. $+p<0.10 ; * p<0.05$; ** $p<0.01$.

QAP correlations and descriptive statistics for the study variables are presented in Table 1. Alpha reliabilities for non-network, multi-item measures are presented in the diagonal where appropriate. The results for the multiple regression QAP analysis are presented in Table 2. Overall, results of the multiple regression QAP show that the study's independent variables, as a group, are stronger predictors of similarity in SICB performance $\left(R^{2}=.13, p<.01\right)$ than for similarity in IICB performance $\left(R^{2}=.08, p<.05\right)$. Among the control variables, similarity in tenure predicted similarity in IICB performance $(\beta=.19, p<.01)$ and SICB performance $(\beta=.23, p<.01)$. Similarity in gender predicted similarity in $\operatorname{SICB}(\beta=.10, p<.05)$, and similarity in trust predicted similarity in IICB $(\beta=.15, p<.05)$.

Hypothesis 1 states that the impact of social influence through direct interaction will be demonstrated if two employees connected by a strong tie also perform more similar ICB than two employees connected by a weaker tie, or not connected at all. This hypothesis was not supported. Strength of tie was not related to either dimension of ICB. While strength of tie exhibited a significant and positive bivariate correlation with similarity in SICB performance, its relationship became non-significant in the multiple regression QAP analysis. This finding suggests that ICB performance is not susceptible to social influence through simple interaction. 
Table 2. Multiple Regression QAP Analysis

$\begin{array}{rr}\underline{\mathrm{IICB}} & \underline{\mathrm{SICB}} \\ \beta & \beta\end{array}$

Control Variables

Gender

Education

Tenure

Perceived Obligations

Trust in Coworkers

Network Variables

\begin{tabular}{|c|c|c|}
\hline Strong Ties & .01 & -.01 \\
\hline Relational Embeddedness & .02 & $.09 *$ \\
\hline Structural Equivalence & $.10 *$ & $.20 * *$ \\
\hline$R^{2}$ & $.08^{*}$ & $.13^{* *}$ \\
\hline
\end{tabular}

Note: $N=33 ; 1056$ observations. Standardized regression coefficients are reported. All variables are similarity matrices. $+p<0.10 ; * p<0.05 ; * * p<0.01$.

Hypothesis 2 states that social influence through normative compliance pressures will be indicated if relationally embedded employees performed similar levels of ICB. Partial support for Hypothesis 2 was found. Two employees who were relationally embedded by virtue of having overlapping relational ties with other coworkers performed more similar levels of SICB $(\beta=.09, p<.05)$. However, relational embeddedness did not predict similarity in the performance of IICB.

Finally, Hypothesis 3 predicts that social influence through symbolic role-taking will be observed if two employees who are structurally equivalent in the network of helping ties will also perform similar levels of ICB. This hypothesis was supported. Structural equivalence significantly predicted similarity in IICB performance $(\beta=.10, p<.05)$ and in SICB performance $(\beta=.20, p<.01)$. Thus, this finding provides evidence that the position an employee occupies in a helping network will define roles, and employees in similar roles (e.g., help-giver) will monitor each other to appropriately orient ICB performance in fulfillment of role obligations.

\section{Discussion}

Despite general acknowledgement that ICB is an inherently social phenomenon, only recently have studies begun to investigate how it is shaped by processes operating within the larger social environment. Of those that have, the social context has been modeled using social 
network methodology, and the results of those studies suggest that an employee's ICB performance is shaped by social influence processes. Social influence is of particular relevance to ICB because expectations for the performance of extra-role behavior like ICB are ill-defined and subject to multiple interpretations. Further, ICB performance can be risky due to the potential costs of helping. As a result of the ambiguity and risks associated with ICB performance, employees are likely to be highly susceptible to the influence of salient social cues centered on helping others. Consistent with these arguments and the findings of prior studies, this study found 1) structurally equivalent employees performed similar levels of IICB and SICB, and 2) relationally embedded employees performed similar levels of SICB. These findings are discussed in the following paragraphs.

As hypothesized, similarly situated employees in a network of helping ties performed similar levels of ICB. Positions in the informal network structure will have different implications for how an employee defines the breadth and scope of their work role (Morrison, 1994). However, unlike formal positions where expectations for performance are more clearly defined, the expectations for different positions in the informal structure are more dubious. What is clear is that network position reflects relative status and access to resources, and hence relative levels of dependence. Therefore, employees who occupy similar positions will experience similar pressures from coworkers related to those resources. This is especially true for positions within instrumental helping networks where the flow (lack of flow) of helping resources can have positive (negative) consequences for task performance and goal achievement.

As noted earlier, relational ties in helping networks are inherently role-based (e.g., help-giver, help-recipient), and research has shown that role-based relational ties produce a strong motivation to effectively meet expectations for the role (Brewer \& Gardner, 1996; Haslam, Powell \& Turner, 2000; Hogg \& Terry, 2000; Markus \& Kitayama, 1991). For example, the role that is associated with positions of high status may have a socially constructed and shared meaning that reflects the following maxim: "To whom much is given, much is expected." Whatever the case may be, perceptions of expected behaviors from one's social role are informed by cues provided by others who occupy similar network positions, and those perceptions will be incorporated into one's perception of their work role.

Consistent with findings of studies examining the link between behavioral conformity and embeddedness, this study found relationally embedded employees to engage in similar levels of SICB. A high level of interconnectedness is thought to enable social influence because normative compliance pressures are stronger and more easily transmitted through embedded ties. Interestingly, relational embeddedness did not predict IICB. It is possible that the performance of SICB is more readily shaped by social influence processes than IICB performance, the latter of which may be more constrained by requirements of the task environment or an employee's access to tangible resources. Because SICB performance involves behaviors such as spending time listening to coworkers, or otherwise supporting coworkers when they face challenges, it may be more elastic and conformable to normative pressures. Further, a greater importance may be placed on SICB performance because of its role for maintaining relational ties. It is more expressive than IICB and better symbolizes the 
value employees place on their relational ties with coworkers (Coleman, 1990).

Hypothesis 1 stated that two employees connected by a strong relational tie will also engage in similar levels of ICB performance. Social information processing theory posits that strong ties promote knowledge-sharing and mutual influence leading to perceptual clarity regarding work-role behavior. However, with regard to ICB performance, no support for this theoretical relationship was found. Several explanations are possible for the non-finding. First, the operationalization of tie strength may not have adequately captured the dynamics of such relationships (i.e., interaction, intensity, self-disclosure, reciprocity). However, its operationalization is similar to that of previous studies that have found links between strong ties and similarity in performance (e.g., Zagenczyk, et al., 2008). Second, the relational ties elicited by the sociometric question may generally reflect the presence of asymmetry in the sample regarding access to helping resources and the relative ability to help in a substantive manner. If so, even reciprocal ties (i.e., strong ties) as indicated by employees' responses would reflect asymmetry to some extent. This explanation would be consistent with the findings that structural equivalence produces similarity in the performance of ICB. Additionally, structural equivalence in the helping network and tie strength in the interaction network are moderately correlated, suggesting that strong relational ties in this study's sample may reflect some degree of resource dependence whereby one employee is better able to perform ICB than the other.

Although not hypothesized, several results of the study warrant comment. First, similarity in IICB and SICB performance were found to be highly correlated $(r=.58, p<.01)$. This mirrors the high correlation found in previous studies using the ICB sub-scales. Because of the high correlation, parsimony in theoretical development may be better served by treating ICB as a unidimensional construct. However, the results of the regression analysis show that the model's independent variables differentially predicted similarity in IICB and SICB performance. As discussed above, the relationship between relational embeddedness and similarity in SICB, but not IICB, suggests that the form of ICB performed may depend on the primary function served by a relational tie (i.e., instrumental or expressive) (Fombrun 1982; Ibarra 1995; Lincoln \& Miller 1979; Podolny \& Baron 1997). Instrumental relational ties address relational needs associated with task performance. Expressive ties facilitate the expression of interpersonal affect and transmission of normative expectations regarding supportive behavior (Coleman, 1990). Since SICB performance better aligns with the expressive function of relational ties then does IICB, it is not surprising that embeddedness is a stronger predictor of it.

Interestingly, as seen in Table 1, similarity in trust had bivariate correlations with strong ties $(r=.08, p<.05)$ and relational embeddedness $(r=.10, p<.05)$. This finding is not surprising given that both strong and relationally embedded ties reflect the same dynamics that lead to high-quality exchange relationships (Cropanzano \& Mitchell, 2005; Weber, Malhotra \& Murnighan, 2005). However, similarity in levels of trust was not correlated with SICB performance, and it was only weakly correlated with IICB performance $(r=.15, p<.10)$. Because IICB is potentially more individually costly, as it involves the transfer of more tangible resources than SICB, perceptions of trust are at least as important for its performance 
as is social influence.

Second, similarity in gender had a positive and significant correlation with SICB and all network variables. A major factor influencing tie formation is homophily, a preference for interacting with similar others (Brass, 2018). The correlation between gender similarity and the network variables supports the findings of previous research that gender similarity is important in tie formation. Similarly, the strong association found in the multiple regression results between similarity in tenure and similarity in ICB performance also supports the importance of homophily in tie formation. Finally, perceived obligations to reciprocate did not predict IICB or SICB performance, but it was strongly associated with similarity in education $(r=.40, p<.01)$. It is possible that this result is due to relative access to helping resources based on education level. If more highly educated employees are better positioned to help, they may be more likely to give help than to receive it. As a result, they may similarly report lower obligations to reciprocate.

\subsection{Limitations}

Before concluding, several caveats are offered here. First, like other studies examining social influence, the hypotheses in this study offered predictions regarding behavioral similarity. A significant, positive correlation or regression coefficient reflects "increased" similarity and a negative coefficient reflects "decreased" similarity (or dissimilarity). Conclusions regarding the actual level of ICB performance (e.g., high vs. low) cannot be inferred from the study's findings. For example, it is possible that structurally equivalent, low status individuals will perform ICB more frequently than structurally equivalent, higher status individuals who possess greater access to helping resources. Research has demonstrated that lower status individuals may frequently perform ICB to manage the impressions of more powerful others (e.g., Bowler \& Brass, 2006). Similarly, infrequent ICB performance may occur among a group of relationally embedded employees if a shared belief exists that ICB performance is merely self-serving ingratiation deserving social disapproval and ridicule. At most, the results of this study suggest that social influence processes can lead employees to "match" the level of ICB performance of their coworkers.

Second, the social influence processes underlying the hypothesized relationships were not directly measured. As such, their presence can only be inferred. Future studies should attempt to more directly establish the link between specific types of social influence that map on to different network properties. In a similar vein, perceptions regarding the extent to which an employee believes that ICB performance is part of their work role (i.e., in-role behavior) was not directly measured. However, perceptions are more malleable than behaviors and the fact that statistically significant relationships were found between similarity in ICB performance (as measured by a supervisor) and network properties (as measured collectively by coworker responses) suggests that this study's design provided for a very conservative test of the hypothesized relationships.

Finally, the limitations of this study are typical of network studies examining interpersonal similarity. The data was collected using a cross-sectional design and does not address causality. Central to the arguments for the use of network analysis is the assumption that 
social ties serve as conduits for social influence. Of course, it is possible that the direction of causation is reciprocal (Brass, 2018). Employees may form ties with coworkers who perform similar levels of ICB. Longitudinal studies are needed to more clearly define the direction of causality.

\section{Conclusion}

The findings of this study indicate that social influence can produce conformity in ICB performance. Uncertain expectations regarding the performance of extra-role behavior like ICB and the associated personal costs of helping others leads employees to attend to and process salient cues provided by their coworkers. Consistent with these arguments and with the findings of prior studies, this study found structural equivalence to predict both IICB and SICB, implicating the robustness of symbolic role-taking as an important predictor of ICB that should receive further research attention in the future.

\section{References}

Adler, P., \& Kwon, S. (2002). Social capital: Prospects for a new concept. The Academy of Management Review, 27, 17-40. https://doi.org/10.5465/amr.2002.5922314

Bamberger, P. A. (2009). Employee help-seeking: Antecedents, consequences and new insights for future research. Research in Personnel and Human Resources Management, 28, 49-98. https://doi.org/10.1108/S0742-7301(2009)0000028005

Bateman, T. S., \& Crant, J. M. (1993). The proactive component of organizational behavior: A measure and correlates. Journal of Organizational Behavior, 14, 103-118. https://doi.org/10.1002/job.4030140202

Bergeron, D. M. (2007). The potential paradox of organizational citizenship behavior: Good citizens at what cost? Academy of Management Review, 32, 1078-1095. https://doi.org/10.5465/amr.2007.26585791

Bhave, D. P., Kramer, A., \& Glomb, T. M. (2010). Work-family conflict in work groups: social information processing, support, and demographic dissimilarity. Journal of Applied Psychology, 95, 145-158. https://doi.org/10.1037/a0017885

Blau, P. (1964). Exchange and power in social life. New York: Wiley.

Bolino, M. C., Turnley, W. H., \& Bloodgood, J. M. (2002). Citizenship behavior and the creation of social capital in organizations. The Academy of Management Review, 27, 505-522. https://doi.org/10.5465/amr.2002.7566023

Bommer, W. H., Miles, E. W., \& Grover. S. L. (2003). Does one good turn deserve another? Coworker influences on employee citizenship. Journal of Organizational Behavior, 24, 181-196. https://doi.org/10.1002/job.187

Borgatti, S. P., Carley, K. M., \& Krackhardt, D. (2006). On the robustness of centrality measures under conditions of imperfect data. Social Networks, 28, 124-136.

https://doi.org/10.1016/j.socnet.2005.05.001 
Borgatti, S. P., Everett, M. G., \& Freeman, L. C. (2002). UCINET 6 for Windows: Software for social network analysis. Harvard: Analytic Technologies.

Bowler, W. M., \& Brass, D. J. (2006). Relational correlates of interpersonal citizenship behavior: A social network perspective. Journal of Applied Psychology, 91, 70-82.

https://doi.org/10.1037/0021-9010.91.1.70

Brass, D. (2018). A social network perspective on organizational citizenship behavior. In P. Podsakoff, S. Mackenzie, \& N. Podsakoff (Eds.), The Oxford handbook of organizational citizenship behavior, (pp. 317-330). New York: Oxford University Press.

https://doi.org/10.1093/oxfordhb/9780190219000.013.25

Brass, D. J., \& Burkhardt, M. E. (1993). Potential power and power use: An investigation of structure and behavior. Academy of Management Journal, 36, 441-470.

https://doi.org/10.2307/256588

Brass, D. J., Butterfield, K. D., \& Skaggs, B. C. (1998). Relationships and unethical behavior: A social network perspective. Academy of Management Review, 23, 14-31.

https://doi.org/10.5465/amr.1998.192955

Brewer, M. B., \& Gardner, W. (1996). Who is this "we"?: Levels of collective identity and self-representations. Journal of Personality and Social Psychology, 71, 83-93.

https://doi.org/10.1037/0022-3514.71.1.83

Burkhardt, M. E. (1994). Social interaction effects following a technological change: A longitudinal investigation. Academy of Management Journal, 37, 869-898.

https://doi.org/10.5465/256603

Chen, Z., Lam, W., \& Zhang, J. A. (2007). Leader-member exchange and member performance: A new look at individual-level negative feedback-seeking behavior and team-level empowerment climate. Journal of Applied Psychology, 92, 202-212.

https://doi.org/10.1037/0021-9010.92.1.202

Chen, Takeuchi, and Shum: A Social Information Processing Perspective of Coworker Influence Organization Science 24(6), pp. 1618-1639. https://doi.org/10.1287/orsc.2013.0820

Cialdini, R. B., \& Goldstein, N. J. (2004). Social Influence: Compliance and conformity. Annual Review of Psychology, 55, 591-621.

https://doi.org/10.1146/annurev.psych.55.090902.142015

Coleman, J. S. (1990). Foundations of social theory. Cambridge, MA: Harvard University Press.

Cropanzano, R., \& Mitchell, M. S. (2005). Social exchange theory: An interdisciplinary review. Journal of Management, 31, 874-900. https://doi.org/10.1177/0149206305279602

Deery, S., Rayton, B., Walsh, J., \& Kinnie, N. (2017). The costs of exhibiting organizational citizenship behavior. Human Resource Management, 56, 1039-1049.

https://doi.org/10.1002/hrm.21815 
Ehrhart, M. G. (2018). Helping in organizations: A review and directions for future research. In P. Podsakoff, S. Mackenzie, \& N. Podsakoff (Eds.), The Oxford handbook of organizational citizenship behavior, (pp. 475-506). New York: Oxford University Press. https://doi.org/10.1093/oxfordhb/9780190219000.013.34

Ferrin, D. L., Dirks, K. T., \& Shah, P. P. (2006). Direct and indirect effects of third-party relationships on interpersonal trust. Journal of Applied Psychology, 91, 870-883.

https://doi.org/10.1037/0021-9010.91.4.870

Fombrun, C. J. (1982). Strategies for network research in organizations. Academy of Management Review, 7, 280-291. https://doi.org/10.5465/amr.1982.4285594

Gibbons, D. E. (2004). Friendship and advice networks in the context of changing professional values. Administrative Science Quarterly, 49, 238-262.

Granovetter, M. (1973). The strength of weak ties. American Journal of Sociology, 78, 1360-1380. https://doi.org/10.1086/225469

Hartman, R. L., \& Johnson, J. D. (1989). Social contagion and multiplexity: Communication networks as predictors of commitment and role ambiguity. Human Communication Research, 15, 523-548. https://doi.org/10.1111/j.1468-2958.1989.tb00198.x

Haslam, S., Powell, C., \& Turner, J. (2001). Social identity, self-categorization, and work motivation: Rethinking the contribution of the group to positive and sustainable organizational outcomes. Applied Psychology, 49, 319 - 339.

https://doi.org/10.1111/1464-0597.00018

Ho, V. T. (2005). Social influence on evaluations of psychological contract fulfillment. Academy of Management Review, 30, 113-128. https://doi.org/10.5465/amr.2005.15281438

Ho, V. T., \& Levesque, L. (2005). With a little help from my friends (and substitutes): Social referents and influence in psychological contract fulfillment. Organization Science, 16, 275-289. https://doi.org/10.1287/orsc.1050.0121

Hogg, M. A., \& Terry, D. (2000). Social identity and self-categorization processes in organizational contexts. Academy of Management Review, 25, 121-140.

https://doi.org/10.5465/amr.2000.2791606

Ibarra, H. (1995). Race, opportunity, and diversity of social circles in managerial networks. Academy of Management Journal, 38, 673-703. https://doi.org/10.5465/256742

Ibarra, H., \& Andrews, S. B. (1993). Power, social influence, and sense-making: Effects of network centrality and proximity on employee perceptions. Administrative Science Quarterly, 38, 277-303. https://doi.org/10.2307/2393414

Katz, D., \& Kahn. R. L. (1978). The social psychology of organizations. New York: Wiley.

Kilduff, M. \& Brass, D. J. (2010). Job design: A social network perspective. Journal of Organizational Behavior, 31, 309-318. https://doi.org/10.1002/job.609 


\section{Macrothink}

International Journal of Human Resource Studies

ISSN 2162-3058

2019, Vol. 9, No. 3

Krackhardt, D. (1988). Predicting with networks: Nonparametric multiple regression analysis of dyadic data. Social Networks, 10, 359-381. https://doi.org/10.1016/0378-8733(88)90004-4

Krackhardt, D. (1999). The ties that torture: Simmelian tie analysis in organizations. Research in the Sociology of Organizations, 16, 183-210.

Krackhardt, D., \& R. Stern (1988). Informal networks and organizational crises: An experimental simulation. Social Psychology Quarterly, 51, 123-140.

https://doi.org/10.2307/2786835

Kram, K. E., \& Isabella, L. A. (1985). Mentoring alternatives: The role of peer relationships in career development. Academy of Management Journal, 28, 110-132.

https://doi.org/10.2307/256064

LePine, J., \& Van Dyne, L. (2001). Voice and cooperative behavior as contrasting forms of contextual performance: Evidence of differential relationships with big five personality characteristics and cognitive ability. The Journal of Applied Psychology, 86, 326-336.

https://doi.org/10.1037/0021-9010.86.2.326

Lincoln, J. R., \& Miller, J. (1979). Work and friendship ties in organizations: A comparative analysis of relational networks. Administrative Science Quarterly, 24, 181-199.

https://doi.org/10.2307/2392493

Markus, H., \& Kitayama, S. (1991). Culture and the self: Implications for cognition, emotion, and motivation. Psychological Review, 98, $224-253$.

https://doi.org/10.1037/0033-295X.98.2.224

McAllister, D. J. (1995). Affect- and cognition-based trust as foundations for interpersonal cooperation in organizations. Academy of Management Journal, 38, $24-59$.

https://doi.org/10.2307/256727

Meyer, G. (1994). Social information processing and social networks: A test of social influence mechanisms. Human Relations, 47, 1013-1047.

https://doi.org/10.1177/001872679404700901

Moorman, R. H. (1993). The influence of cognitive and affective based job satisfaction measures on the relationship between satisfaction and organizational citizenship behavior. Human Relations, 46, 759-776. https://doi.org/10.1177/001872679304600604

Morrison, E. (1994). Role definitions and organizational citizenship behavior: The importance of the employee's perspective. Academy of Management Journal, 37, 1543-1567. https://doi.org/10.2307/256798

Ocampo, L., Acedillo, V., Bacunador, A. M., Balo, C. C., Lagdameo, Y. J., \& Tupa, N. S. (2018). A historical review of the development of organizational citizenship behavior (OCB) and its implications for the twenty-first century. Personnel Review, 47(4), 821-862.

https://doi.org/10.1108/PR-04-2017-0136

Organ, D. W. (1988). Organizational citizenship behavior: The good soldier syndrome. 
Lexington, MA: Lexington Books.

Organ, D. W. (1997). Organizational citizenship behavior: It's construct clean up time. Human Performance, 10, 85-97. https://doi.org/10.1207/s15327043hup1002_2

Podolny, J. M., \& Baron, J. N. (1997). Resources and relationships: Social networks and mobility in the workplace. American Sociological Review, 62, 673-693.

https://doi.org/10.2307/2657354

Podsakoff, N. P., Whiting, S. W., Podsakoff, P. M., \& Blume, B. D. (2009). Individual- and organizational-level consequences of organizational citizenship behaviors: A meta-analysis. Journal of Applied Psychology, 94, 122-141. https://doi.org/10.1037/a0013079

Raider, H., \& Krackhardt, D. J. (2001). Intra-organizational networks. In J. Baum (Ed.), Companion to organizations, (pp. 58-74). Oxford, UK: Blackwell.

https://doi.org/10.1002/9781405164061.ch2

Rawlins, W. K. (1992). Friendship matters: Communication, dialectics, and the life course. Hawthorne, NY: Aldine.

Rice, R. E., \& Aydin, C. (1991). Attitudes toward new organizational technology: Network proximity as a mechanism for social information processing. Administrative Science Quarterly, 36, 219-244. https://doi.org/10.2307/2393354

Salancik, G. R., \& Pfeffer, J. (1978). A social information processing approach to job attitudes and task design. Administrative Science Quarterly, 23, 224-253.

https://doi.org/10.2307/2392563

Settoon, R. P., \& Mossholder. K. W. (2002). Relationship quality and relationship context as antecedents of person- and task-focused interpersonal citizenship behavior. Journal of Applied Psychology, 87, 255-267. https://doi.org/10.1037/0021-9010.87.2.255

Shah, P. P. (1998). Who are employees' social referents? Using a network perspective to determine referent others. Academy of Management Journal, 43, 249-268.

https://doi.org/10.2307/256906

Sherony, K. M., \& Green, S. G. (2002). Coworker exchange: Relationships between coworkers, leader-member exchange, and work attitudes. Journal of Applied Psychology, 87, 542-548. https://doi.org/10.1037/0021-9010.87.3.542

Umphress, E. E., Labianca, G., Brass, D. J., Kass, E., \& Scholten, L. (2003). The role of instrumental and expressive social ties in employees' perceptions of organizational justice. Organization Science, 14, 738-753. https://doi.org/10.1287/orsc.14.6.738.24865

Venkataramani, V. \& Dalal, R. S. (2007). Who helps and harms whom? Relational antecedents of interpersonal helping and harming in organizations. Journal of Applied Psychology. 92, 952-966. https://doi.org/10.1037/0021-9010.92.4.952

Vinarski-Peretz, H., Binyamin, G., \& Carmeli, A. (2011). Subjective relational experiences and employee innovative behaviors in the workplace. Journal of Vocational Behavior, 78, 


\section{Macrothink \\ International Journal of Human Resource Studies \\ ISSN 2162-3058 2019, Vol. 9, No. 3}

290-304. https://doi.org/10.1016/j.jvb.2010.09.005

Wasserman, S., \& Faust, K. (1994). Social network analysis: Methods and applications. Cambridge, UK: Cambridge University Press. https://doi.org/10.1017/CBO9780511815478

Weber, J. M., Malhotra, D., \& Murnighan, J. K. (2005). Normal acts of irrational trust: Motivated attributions and the trust development process. In B. M. Staw \& R. M. Kramer (Eds.), Research in Organizational Behavior. https://doi.org/10.1016/S0191-3085(04)26003-8

Williams, L. J., \& Anderson, S. E. (1991). Job satisfaction and organizational commitment as predictors of organizational citizenship and in-role behavior. Journal of Management, 17, 601-617. https://doi.org/10.1177/014920639101700305

Zagenczyk, T. J., Gibney, R., Murrell, A. J., \& Boss, S. R. (2008). Friends don't make friends good citizens, but advisors do. Group and Organization Management, 33, 760-780.

https://doi.org/10.1177/1059601108326806

\section{Copyright Disclaimer}

Copyright for this article is retained by the author(s), with first publication rights granted to the journal.

This is an open-access article distributed under the terms and conditions of the Creative Commons Attribution license (http://creativecommons.org/licenses/by/4.0/). 